\title{
Positive allosteric modulation of P2X7 promotes apoptotic cell death over lytic cell death responses in macrophages
}

\author{
Stefan Bidula ${ }^{1}$, Kshitija Dhuna², Ray Helliwell ${ }^{2}$ and Leanne Stokes (1)
}

\begin{abstract}
P2X7 is an ATP-gated ion channel that is highly expressed by leukocytes, such as macrophages. Here, P2X7 has been demonstrated to be involved in the regulation of various cell death pathways; including apoptosis, pyroptosis, necrosis, and autophagy. However, cell death induction via P2X7 is complex and is reliant upon the nature of the stimulus, the duration of the stimulus, and the cell type investigated. Previous reports state that high extracellular ATP concentrations promote osmotic lysis, but whether positive allosteric modulation of P2X7 in the presence of lower concentrations of ATP condemns cells to the same fate is unknown. In this study, we compared cell death induced by high ATP concentrations, to cell death induced by compound $\mathrm{K}$, a recently identified and potent positive allosteric modulator of P2X7. Based on our observations, we propose that high ATP concentrations induce early cell swelling, loss of mitochondrial membrane potential, plasma membrane rupture, and LDH release. Conversely, positive allosteric modulation of P2X7 primarily promotes an intrinsic apoptosis pathway. This was characterised by an increase in mitochondrial $\mathrm{Ca}^{2+}$, accelerated production of mitochondrial ROS, loss of mitochondrial membrane permeability in a Bax-dependent manner, the potential involvement of caspase-1, and caspase-3, and significantly accelerated kinetics of caspase-3 activation. This study highlights the ability of positive allosteric modulators to calibrate P2X7-dependent cell death pathways and may have important implications in modulating the antimicrobial immune response and in the resolution of inflammation.
\end{abstract}

\section{Introduction}

P2X7 is an ATP-gated ion channel expressed predominantly on immune cells such as macrophages. Here, it plays key roles within inflammation via the activation of the NLRP3-caspase-1 inflammasome, release of pro- and anti-inflammatory mediators (e.g. IL-1 $\beta$, IL-18, Annexin A1), shedding of transmembrane proteins (i.e. CD62L, CD23), and regulation of cell death processes (necrosis, apoptosis, pyroptosis, autophagy) ${ }^{1}$. To date, the involvement of P2X7 in regulating cell death has proven to be

Correspondence: Leanne Stokes (I.stokes@uea.ac.uk)

'School of Pharmacy, University of East Anglia, Norwich Research Park, Norwich, United Kingdom

${ }^{2}$ School of Health and Biomedical Sciences, RMIT University, Bundoora, VIC 3083, Australia

Edited by A. Oberst complex and varied, and is governed by the cell type, nature of the stimulus, and duration of the stimulus ${ }^{2}$. Prolonged activation of P2X7 has been linked to typical morphological changes during apoptosis, such as cell blebbing, cell shrinkage, nuclear fragmentation, and chromatin condensation ${ }^{3}$. Moreover, P2X7 can regulate cell death via caspase- 8 and caspase-9; stimulating ROS production, mitochondrial dysfunction, cytochrome $\mathrm{c}$ release, and caspase-3/7 activation ${ }^{3-6}$. Conversely, P2X7 can also activate the canonical (caspase-1 dependent) pyroptosis pathway in LPS-primed cells. Here, ATP can function as a damage-associated molecular pattern (DAMP), resulting in cell blebbing, cytoplasmic swelling, release of cytokines and alarmins, and ultimately lytic cell death $^{7-10}$. Furthermore, ATP can activate the noncanonical pyroptosis pathway following LPS priming. In

\section{(c) The Author(s) 2019}

(c) (i) Open Access This article is licensed under a Creative Commons Attribution 4.0 International License, which permits use, sharing, adaptation, distribution and reproduction cc) in any medium or format, as long as you give appropriate credit to the original author(s) and the source, provide a link to the Creative Commons license, and indicate if changes were made. The images or other third party material in this article are included in the article's Creative Commons license, unless indicated otherwise in a credit line to the material. If material is not included in the article's Creative Commons license and your intended use is not permitted by statutory regulation or exceeds the permitted use, you will need to obtain permission directly from the copyright holder. To view a copy of this license, visit http://creativecommons.org/licenses/by/4.0/. 
this pathway caspase- 11 in mice, or caspase- 4 and -5 in humans, can partially cleave pannexin-1 channels, resulting in $\mathrm{K}^{+}$efflux and release of ATP into the extracellular space ${ }^{11}$.

P2X7 is therefore an attractive target to manipulate cell death pathways in scenarios where the type of death is important; for example, during cancer, or following infection with intracellular pathogens such as Mycobacterium tuberculosis or Toxoplasma gondii ${ }^{12}$. Moreover, cancer cells and pathogens can subvert the immune response by employing the use of ectonucleotidases such as CD39 and CD73 to limit the availability of ATP, or by pathogens hiding within cells to evade recognition by host immune receptors ${ }^{13,14}$. Therefore, the ability to enhance or accelerate P2X7-dependent cell death pathways in these scenarios could prove critical in the resolution of infection or inflammatory situations.

One way in which the activity of P2X7 can be modified is via allosteric modulation. We recently identified a novel positive allosteric pocket within the central vestibule of human P2X7 that is potentiated by 'steroid-like' triterpenoid glycosides, termed ginsenosides ${ }^{15,16}$. Particularly, compound $\mathrm{K}$ (CK), an in vivo metabolite from the medicinal herb Panax ginseng had a profound effect on P2X7-dependent responses and could potentiate ATPinduced channel opening at nanomolar concentrations ${ }^{15}$. Moreover, CK could enhance $\mathrm{Ca}^{2+}$ signalling, formation of the macropore, and enhance cell death of macrophages to a non-lethal concentration of $\mathrm{ATP}^{15}$. However, the mechanism of cell death regulated by P2X7 in the presence of positive allosteric modulators is currently unknown.

Our aim in this study was to compare the effects of high ATP concentrations or positive allosteric modulation by CK on the induction of P2X7-dependent cell death pathways and elucidate the cell death mechanism employed in murine macrophages. We describe a mechanism whereby positive allosteric modulation of P2X7 primarily promotes an intrinsic apoptosis pathway, characterised by an increase in mitochondrial $\mathrm{Ca}^{2+}$, accelerated production of mitochondrial ROS, loss of mitochondrial membrane permeability in a Bax-dependent manner, the potential involvement of caspases-1, and -3 , and significantly accelerated caspase-3/7 activation.

\section{Materials and methods Cell culture}

Mouse macrophage cell line J774.2 (obtained from ECACC General Cell Culture Collection, UK) were maintained in RPMI-1640 media containing L-glutamine (Life Technologies, Fisher Scientific, UK) supplemented with $10 \%$ foetal bovine serum (Sigma US origin, F2442) and $100 \mathrm{U} / \mathrm{ml}$ penicillin plus $100 \mu \mathrm{g} / \mathrm{mL}$ streptomycin (Fisher Scientific, UK). Cells were maintained at $37^{\circ} \mathrm{C}$ in a humidified incubator supplied with $5 \% \mathrm{CO}_{2}$. Cells were not tested for mycoplasma contamination.

For cell stimulations, stock ATP (A7699, Sigma-Aldrich, UK) was prepared as a solution of $100 \mathrm{mM}$ in distilled water and $\mathrm{pH}$ was corrected to 7.4 with $5 \mathrm{M} \mathrm{NaOH}$. Aliquots were frozen at $-20^{\circ} \mathrm{C}$ and used once. Ginsenoside CK (CAS\#39262-14-1, purity >98\%) was from Chemfaces, China and was prepared as $10 \mathrm{mM}$ stock in DMSO.

\section{Flow cytometry}

To quantify cell surface expression of murine P2X7 (mP2X7), $5 \times 10^{5}$ cells were pelleted prior to resuspension in primary mouse anti-mouse P2X7 antibody (Hano43; Enzo Life Sciences, UK) at a dilution of 1:20 in cold PBS/ $0.5 \%$ BSA buffer. Cells were stained for $1 \mathrm{~h}$ on ice and then washed with PBS/0.5\% BSA buffer. This was followed by staining with a goat anti-rat IgG Alexa488 secondary antibody (Fisher Scientific, UK) at 1:100 dilution for $1 \mathrm{~h}$ on ice. Following washing with PBS/0.5\% BSA buffer, cells were re-suspended in PBS/0.5\% BSA buffer for acquisition on a CytoFLEX flow cytometer (Beckman Coulter, USA; laser excitation, $488 \mathrm{~nm}$; emission detection, 533/30 nm). Data were analysed using CytExpert software (Beckman Coulter; version 2.1).

\section{Dye uptake experiments}

For YOPRO-1 dye uptake experiments cells were plated at a density of $2 \times 10^{4}$ cells/well in complete RPMI 1640 media $(100 \mu \mathrm{L}$ per well) in poly-D-lysine coated 96-well plates. Media was removed using a manual multichannel pipette and replaced with a low divalent cation buffer $(145 \mathrm{mM} \mathrm{NaCl}, 2 \mathrm{mM} \mathrm{KCl}, 13 \mathrm{mM}$ D-glucose, $10 \mathrm{mM}$ HEPES and $0.1 \mathrm{mM} \mathrm{CaCl}_{2}, \mathrm{pH}$ 7.3) containing $2 \mu \mathrm{M}$ YOPRO-1 iodide (Life Technologies catalogue number Y3663). For most experiments, ginsenosides $(10 \mu \mathrm{M})$ were co-injected simultaneously with the agonist using a Flexstation 3 microplate reader (Molecular Devices, UK). Ginsenosides and agonist were prepared at 10X final concentration in the compound plate. Dye uptake over time was recorded using an excitation wavelength of $488 \mathrm{~nm}$ and an emission wavelength of $520 \mathrm{~nm}$ on the Flexstation 3 (6 reads/well, PMT setting medium). Basal fluorescence measurements were acquired for $40 \mathrm{sec}$ followed by automatic injection of agonist and the kinetic measurement of fluorescence intensity was performed for $300 \mathrm{sec}$ using Softmax Pro v5.4 software (Molecular Devices). Measurements were performed in triplicate and repeated in three independent experiments. Dye uptake responses were calculated as area under the curve from 50-300 sec using zero baseline normalised data.

\section{Intracellular calcium measurements}

For calcium measurements cells were plated at a density of $2 \times 10^{4}$ cells/well in complete RPMI 1640 media 
(100 $\mu \mathrm{L}$ per well) in poly-D-lysine coated 96-well plates. Cells were loaded with $2 \mu \mathrm{M}$ Fura-2AM (Fisher Scientific) in HBSS buffer containing $250 \mu \mathrm{M}$ sulfinpyrazone (Sigma-Aldrich, UK) for $40-60 \mathrm{~min}$ at $37^{\circ} \mathrm{C}$. Following loading, buffer was removed using a multichannel pipette and replaced with standard extracellular buffer or low divalent buffer. Cells were warmed for $10 \mathrm{~min}$ before measurements were started. Fura-2 was measured at excitation wavelengths $340 \mathrm{~nm}$ and $380 \mathrm{~nm}$ with emission wavelength $520 \mathrm{~nm}$ using a Flexstation 3 plate reader. Sampling interval was $3.5 \mathrm{sec}$ and 3 reads/well. Basal fluorescence measurements were acquired for $40 \mathrm{sec}$ followed by automatic injection of agonist and the kinetic measurement of fluorescence intensity was performed for 300 sec. Fura- 2 ratio was calculated using Softmax Pro v5.4.5 and responses measured using area under curve kinetic reduction.

For simultaneous Fluo-4 and Rhod-2 calcium measurements, J774 cells were plated at a density of $5 \times 10^{4}$ cells/well in complete RPMI 1640 media $(100 \mu \mathrm{L}$ per well) on poly-D-lysine coated 96-well plates. Cells were loaded with $2 \mu \mathrm{M}$ Rhod-2AM in HBSS buffer containing $2 \mathrm{mM}$ probenecid (Fisher Scientific, UK) for $60 \mathrm{~min}$ at $37^{\circ} \mathrm{C}$. Loading buffer was removed and replaced with HBSS containing $2 \mu \mathrm{M}$ Fluo- $4 \mathrm{AM}$ and $2 \mathrm{mM}$ probenecid. This was incubated for $40 \mathrm{~min}$ at $37^{\circ} \mathrm{C}$. Loading buffer was removed and replaced with extracellular buffer containing $2 \mathrm{mM} \mathrm{CaCl} 2$ (zero magnesium) and $1 \mathrm{mM}$ probenecid. Cells were warmed to $37^{\circ} \mathrm{C}$ for $10 \mathrm{~min}$ in the Flexstation 3 before measurements were started. Fluo- 4 fluorescence was measured at excitation $490 \mathrm{~nm}$ and emission $520 \mathrm{~nm}$ (cut-off $515 \mathrm{~nm}$ ) using 6 reads/well on PMT medium; Rhod-2 fluorescence was measured at excitation $550 \mathrm{~nm}$ and emission $580 \mathrm{~nm}$ (cut-off $570 \mathrm{~nm}$ ) using 6 reads/well on PMT medium using a dual wavelength protocol. Agonists were prepared at 10X final concentration and automatically injected at $30 \mathrm{sec}$. Recordings were made for $300 \mathrm{sec}$ in Flex mode allowing analysis of the calcium signals immediately after injection of agonists $+/-$ modulators. Following completion of recordings, further measurements were made in kinetic mode every $60 \mathrm{sec}$ for $90 \mathrm{~min}$ to follow calcium changes over prolonged time. Data were collected from three independent experiments from triplicate wells. Data were analysed by quantifying the fluorescence change over $300 \mathrm{sec}$ by area under curve calculations in Softmax Pro software v5.4.5 (normalised by zero baseline). Kinetic profiles follow absolute fluorescence values over the time-course of the experiment.

\section{Membrane potential assays}

J774 cells were plated at a density of $2 \times 10^{4}$ cells/well in complete RPMI 1640 media (100 $\mu \mathrm{L}$ per well) on poly-Dlysine coated 96-well plates. Cells were left to adhere overnight. Membrane potential blue (Molecular Devices) was prepared in standard extracellular buffer. Media was removed from the plate using a multichannel pipette and $180 \mu \mathrm{L}$ of membrane potential blue solution added to the cells. The plate was then incubated at $37^{\circ} \mathrm{C}$ in a humidified incubator for $30 \mathrm{~min}$. Agonists were prepared at 10X final concentration and added to a drug plate. Fluorescence was measured using a Flexstation 3 multimode plate reader using excitation wavelength $525 \mathrm{~nm}$ and emission wavelength $565 \mathrm{~nm}$ (auto cut-off $550 \mathrm{~nm}$ ). PMT setting was medium and 3 reads/well. Each column was read for $180 \mathrm{sec}(2 \mathrm{sec}$ intervals) and then recordings continued at a sample rate of 1 reading $/ 60 \mathrm{sec}$ for $90 \mathrm{~min}$. Data were collected from three independent experiments from triplicate wells. Data were then analysed by quantifying the fluorescence change over $180 \mathrm{sec}$ using area under curve calculations in Softmax Pro software v5.4.5 (normalised by zero baseline).

\section{Lactate dehydrogenase (LDH) assay}

LDH release was quantified using a Pierce ${ }^{\mathrm{TM}} \mathrm{LDH}$ Cytotoxicity Assay Kit (Fisher Scientific) and was conducted as per manufacturer's instructions. In brief, $50 \mu \mathrm{L}$ of cell supernatant was incubated with $50 \mu \mathrm{L}$ of the $\mathrm{LDH}$ reaction mixture for $30 \mathrm{~min}$ at $\mathrm{RT}$ prior to measuring absorbance at $490 \mathrm{~nm}$ on a Flexstation 3 plate reader. To calculate toxicity, the background absorbance (spontaneous LDH release) was subtracted from the sample values. The total amount of LDH contained in the cells was obtained following lysis of the cells. The LDH absorbance values obtained from the samples were then converted and represented as a percentage of the overall LDH contained within the cells.

\section{Cell viability}

Viability experiments were performed using the CellTiter $96^{\circ}$ Aqueous Non-Radioactive Cell Proliferation assay (Promega, UK), a colorimetric method for determining the number of viable cells. J774 cells were plated at $2 \times 10^{4}$ cells/well in RPMI 1640 media supplemented with $1 \%$ or $10 \%$ serum and left for $24 \mathrm{~h}$ under normal growth conditions. Treatments were then added to the cells ( $2 \times$ final concentration) and incubated for a further 6 or $24 \mathrm{~h}$. MTS solution $(20 \mu \mathrm{L})$ was added to media in each well $4 \mathrm{~h}$ before the stipulated end point time. Absorbance was measured at $490 \mathrm{~nm}$ using a Clariostar plate reader (BMG Labtech, UK) or a Flexstation 3 plate reader.

We also used an AlamarBlue metabolic assay to measure cell viability. For these experiments resazurin $(0.1 \mathrm{mg} / \mathrm{mL}$ in PBS; Sigma-Aldrich) was added to the cells and incubated for a further $2 \mathrm{~h}$ at $37^{\circ} \mathrm{C}$. Fluorescence was measured on a Flexstation 3 plate reader (excitation, $570 \mathrm{~nm}$; emission, $585 \mathrm{~nm}$ ). The background fluorescence of the media alone in the absence of cells was subtracted from all samples. Data were collected from triplicate wells 
for each experiment and experiments performed three independent times.

The Multi-tox-fluor multiplex cytotoxicity assay (Promega, UK) was used, which measures the activity of two proteases in both live and dead cells. The multi-tox fluor multiplex cytotoxicity assay was conducted as per manufacturer's instructions. Equal parts of the viable cell protease substrate (GF-AFC Substrate) and the dead-cell protease substrate (bis-AAF-R110 Substrate) were mixed together in the assay buffer and $100 \mu \mathrm{L}$ was added to cells $(200 \mu \mathrm{L}$ [ $300 \mu \mathrm{L}$ total volume]) for the final $30 \mathrm{~min}$ of incubation time at $37^{\circ} \mathrm{C}$. Fluorescence was then measured in a Flexstation 3 (Live-cell fluorescence measured at an excitation of $400 \mathrm{~nm}$ and emission of $505 \mathrm{~nm}$; dead-cell fluorescence measured at an excitation of $485 \mathrm{~nm}$ and emission of $520 \mathrm{~nm}$ ).

To inhibit cell death, caspase inhibitors for pan-caspases, caspase-1, caspase-3, and caspase-8 (Z-VAD-FMK, (AcYVAD-CMK, Z-DEVD-FMK [and Ac-DEVD-CHO], and Z-IETD-FMK, respectively) or MCC950 were used at $10 \mu \mathrm{M}$ and pre-incubated for $2 \mathrm{~h}$ prior to stimulation. Inhibitors were from Santa Cruz (Z-IETD-FMK and Ac-YVAD-CMK) or Bio-Techne (Z-VAD-FMK, Z-DEVD-FMK, MCC950). To scavenge mitochondrial ROS, mitoTEMPO (Sigma) was used at $25 \mu \mathrm{M}$, to inhibit Bax the Bax V5 peptide (BioTechne, UK) was used at $200 \mu \mathrm{M}$, to chelate $\mathrm{Ca}^{2+}$ EGTA was used at a concentration of $5 \mathrm{mM}$.

\section{Caspase-3/7 activation}

Caspase-3/7 activation in cells was quantified using an EarlyTox $^{\mathrm{TM}}$ Caspase-3/7 NucView 488 kit (Molecular Devices, UK) according to manufacturer's instructions. This method utilises a substrate consisting of a fluorogenic DNA dye coupled to the caspase-3/7 DEVD recognition sequence. When the substrate permeates the plasma membrane, caspase-3/7 can cleave the substrate, releasing a high affinity dye that stains the nucleus. In brief, J774 cells were plated at $2 \times 10^{4}$ cells/well in RPMI 1640 media supplemented with $10 \%$ serum or HBSS (Fisher Scientific, UK) supplemented with $20 \mathrm{mM}$ HEPES and left for $24 \mathrm{~h}$ under normal growth conditions. Treatments were added to the cells $(2 \times$ final concentration) and incubated for either $24 \mathrm{~h}$ under normal growth conditions or placed directly in an ImageXpress ${ }^{\circledR}$ Widefield system (Molecular Devices, Australia) for $12 \mathrm{~h}$ to measure the kinetics of caspase-3/7 activation. The caspase-3/7 NucView substrate was added to the cells at a final concentration of $5 \mu \mathrm{M}$, incubated at room temperature for $30 \mathrm{~min}$, and protected from light. To inhibit caspase activation, cells were incubated overnight with $10 \mu \mathrm{M}$ of the pan-caspase inhibitor Z-VAD-FMK (BioTechne, UK). Caspase-3/7-positive cells were observed via microscopy (FITC filter; Leica, Germany) and caspase-3/7 activation kinetics were quantified using the ImageXpress $^{\circledast}$ (laser excitation, $500 \mathrm{~nm}$; emission detection, $530 \mathrm{~nm}$ ). The area of cells was quantified using Fiji software v.2.

\section{Measurement of reactive oxygen species (ROS)}

The production of either cellular ROS or mitochondrial ROS (mtROS) was quantified using 2',7' -dichlorofluorescin diacetate (DCFDA; Molecular Probes, UK) or MitoSOX $^{\mathrm{TM}}$ Red reagent (Molecular Probes, Fisher Scientific, UK), respectively. J774 cells were plated at $2 \times 10^{4}$ cells/well (96-well black clear bottom plates) in phenol red-free RPMI 1640 media supplemented with $10 \%$ serum and left for $24 \mathrm{~h}$ under normal growth conditions. For the quantification of cellular ROS, cells were loaded with a final concentration of $5 \mu \mathrm{M}$ DCFDA for $45 \mathrm{~min}$ at $37^{\circ} \mathrm{C}$ prior to removal of the dye and the addition of treatments in low divalent assay buffer. DCFDA fluorescence was detected on a Flexstation 3 plate reader (excitation, $492 \mathrm{~nm}$; emission, $520 \mathrm{~nm}$ ). For the quantification of mtROS, cells were loaded with a final concentration of $5 \mu \mathrm{M}$ MitoSOX ${ }^{\mathrm{TM}}$ Red reagent for $10 \mathrm{~min}$ at $37^{\circ} \mathrm{C}$ prior to removal of the dye and the addition of treatments in low divalent assay buffer. MitoSOX ${ }^{\mathrm{TM}}$ red fluorescence was detected on a Flexstation 3 plate reader (excitation, $510 \mathrm{~nm}$; emission, $580 \mathrm{~nm}$ ). Readings were taken every $15 \mathrm{~min}$ for 60 or $105 \mathrm{~min}$ for cellular and mitochondrial ROS, respectively. Samples were read using PMT low and either 30 or 50 reads per well for cellular ROS and mitochondrial ROS, respectively. For the MitoSOX ${ }^{\mathrm{Tm}}$ assays in the presence of $5 \mathrm{mM}$ EGTA, readings were taken using kinetic mode on the Flexstation 3 with readings being taken every $60 \mathrm{sec}$ for $120 \mathrm{~min}$.

\section{Measurement of mitochondrial membrane potential}

Mitochondrial membrane potential was quantified using tetramethylrhodamine methyl ester (TMRM; Molecular Probes, Fisher Scientific). J774 cells were plated at $2 \times 10^{4}$ cells/well (96-well plate) in RPMI 1640 media supplemented with $10 \%$ serum and left for $24 \mathrm{~h}$ under normal growth conditions. Cells were stimulated with their respective treatments for 2, 4, or $24 \mathrm{~h}$ in RPMI 1640 media containing $10 \%$ serum. The media was replaced with RPMI 1640 containing $100 \mathrm{nM}$ TMRM for the final $30 \mathrm{~min}$ of cell treatment and incubated at $37^{\circ} \mathrm{C}$. Cells were washed with pre-warmed phenol red-free RPMI and cells were visualised via fluorescent microscopy (RFP/ TRITC filter, emission detection at $574 \mathrm{~nm}$ ). The percentage of TMRM positive cells was quantified using Fiji v.2. One image per well was obtained (triplicate wells per treatment) on a Leica DM16000 inverted microscope (Hoescht exposure $888.9 \mathrm{~ms}$; TMRM exposure $1.2 \mathrm{~s}$ ) using Leica application suite version 2.8.1. 


\section{Statistical analysis}

Graphs were plotted using GraphPad Prism version 7 (La Jolla, USA). Concentration-response curves were fitted using a log (agonist) vs response-variable slope (four parameter) best-fit equation. Error bars are standard deviation. Data were analysed for statistical significance using one-way ANOVA or two-way ANOVA with posttests as appropriate, including multiple comparisons testing (GraphPad Prism). Significance was taken as $P<0.05$.

\section{Results}

\section{CK potentiates calcium mobilisation, YOPRO-1 uptake} responses, and augments cell death of $\mathrm{J774}$ macrophages in a P2X7-dependent manner

We have previously reported that CK could positively modulate $\mathrm{P} 2 \mathrm{X} 7^{15}$. P2X7 is expressed on 7774 cells (Supplementary Fig. 1) and we confirmed that CK potentiates P2X7-induced $\mathrm{Ca}^{2+}$ responses. Pre-treatment with the selective P2X7 antagonist AZ10606120 abolished the ATP + CK mediated $\mathrm{Ca}^{2+}$ response (Fig. 1a, b). Furthermore, CK could enhance both the maximal ATP-induced $\mathrm{Ca}^{2+}$ response from $\mathrm{J774}$ macrophages and caused a leftward-shift in the $\mathrm{EC}_{50}$, suggesting an increase in the sensitivity of cells to ATP (Fig. 1c). A characteristic feature of P2X7 activation is the formation of a large secondary pore, which allows impermeant molecules to traverse the membrane. Upon pore formation, YOPRO-1 can enter the cell, bind to DNA/RNA and fluoresce. CK could significantly potentiate ATP-induced YOPRO-1 dye uptake, enhancing both the maximal uptake of YOPRO-1 and reducing the concentration of ATP required to elicit this response (Fig. 1d, e).

P2X7 can contribute to inflammation via the regulation of cell death, therefore we investigated the effects of the positive modulator $\mathrm{CK}$ on enhancing macrophage cell death. It is well established that high concentrations ofATP in the $\mathrm{mM}$ range can induce cell death in numerous cell types expressing $\mathrm{P} 2 \mathrm{X} 7^{1,2}$. Following stimulation of 5774 cells with a range of ATP concentrations $100 \mu \mathrm{M}$ to $5 \mathrm{mM}$, only the $3 \mathrm{mM}$ and $5 \mathrm{mM}$ concentrations were capable of eliciting cell death (reducing cell viability to $29.4 \%$ and $38.3 \%$ of control, respectively; Fig. 1f, g). This effect could be reversed with AZ10606120 $(10 \mu \mathrm{M})$ (Fig. 1f, g).

To investigate the effect of CK on potentiation of P2X7mediated cell death, we selected $500 \mu \mathrm{M}$ ATP as it induces robust responses at P2X7 and is non-lethal (Fig. 1d). CK could not potentiate cell death to ATP concentrations lower than this $(200 \mu$ M; Supplementary Fig. 2). We found that CK could enhance ATP-dependent cell death in a concentration-dependent manner, with $10 \mu \mathrm{M}$ CK causing the most reduction in cell viability after $24 \mathrm{~h}$ (Fig. 2a, b). Moreover, CK had very little effect on cell viability on its own and therefore required the presence of ATP to elicit its cytotoxic effects (Fig. 2b). Notably, the cytotoxic effects of ATP in combination with $10 \mu \mathrm{M} \mathrm{CK}$ could be reversed by the addition of AZ10606120 (Fig. 2b).

Previous reports state that P2X7 activation in J774 macrophages by high ATP concentrations stimulates cell death via osmotic lysis, characterised by cell swelling and rupture $^{17}$. In agreement, we show that cells exposed to $3 \mathrm{mM}$ ATP swell to almost twice the size of cells exposed to $500 \mu \mathrm{M}$ ATP and swelling was dependent on P2X7 but was not dependent on the NLRP3 inflammasome (Fig. 2c) as pre-treatment with the NLRP3 inhibitor, MCC950, had no effect (Fig. 2c). Cell swelling induced by $3 \mathrm{mM}$ ATP was associated with a significant increase in the release of lactate dehydrogenase (LDH), which was not observed following stimulation of P2X7 by ATP + CK after $24 \mathrm{~h}$ (Fig. 2d).

\section{CK potentiates cell death in a caspase-dependent manner}

We investigated whether cell death induced by $3 \mathrm{mM}$ ATP or by ATP + CK was caspase dependent by preincubating with the pan-caspase inhibitor Z-VAD-FMK. Under these conditions, CK was unable to augment ATPinduced cell death (Fig. 3a, b), however the lytic cell death induced by $3 \mathrm{mM}$ ATP was largely unaffected (Fig. 3a, b). We next proceeded to investigate the differences in P2X7induced cell death by the two stimuli by using inhibitors of specific caspases. In order to quantify cell death at an earlier time-point $(6 \mathrm{~h})$ we utilised a multi-tox fluor cytotoxicity assay allowing us to measure live cells and dead cells simultaneously. After $6 \mathrm{~h}$ ATP + CK increased cell death by 3.6-fold (Fig. 3c), and this could be inhibited by AZ10606120. This ATP + CK-induced cell death was partly reversed by inhibitors for caspase- 1 , caspase- 3 , and MCC950, but not by inhibitors of caspase-8 (Fig. 3c). This trend was also observed over $24 \mathrm{~h}$, although the effects of caspase inhibitors did not reach statistical significance (Fig. 3d). Conversely, death induced by $3 \mathrm{mM}$ ATP was much more pronounced at the $6 \mathrm{~h}$ time-point with a 16.8 fold increase (Fig. 3e) and could not be reversed by any of the caspase inhibitors tested at either time-point (Fig. 3f). We measured activation of caspase-3/7 using a Nucview fluorescent substrate and found ATP + CK could stimulate caspase-3/7 activation and this was inhibited by the caspase-3 inhibitor Ac-DEVD-CHO (Fig. 3g).

\section{Kinetics of caspase-3/7 activation are regulated by $\mathrm{P} 2 \mathrm{X7}$}

Numerous studies have implicated a role for P2X7 in the activation of pro-apoptotic caspases 8,9 , and $3^{4}$. Following stimulation of cells with ATP + CK, almost all the cells were caspase-3/7-positive after 24h (93.2\%) compared to $\sim 10 \%$ for $500 \mu \mathrm{M}$ ATP alone (Fig. 4a, b). Moreover, caspase-3/7 activation was inhibited by 
A $\rightarrow 200 \mu \mathrm{MATP}$

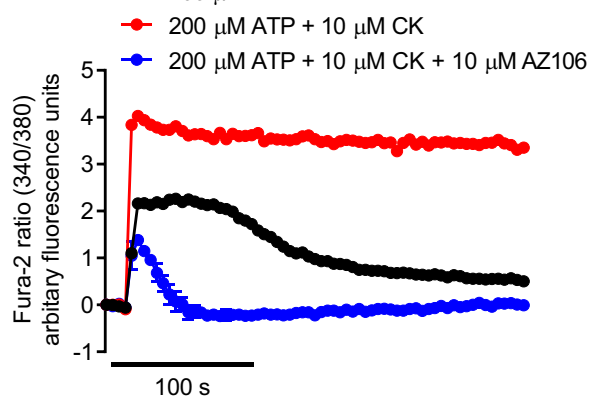

C

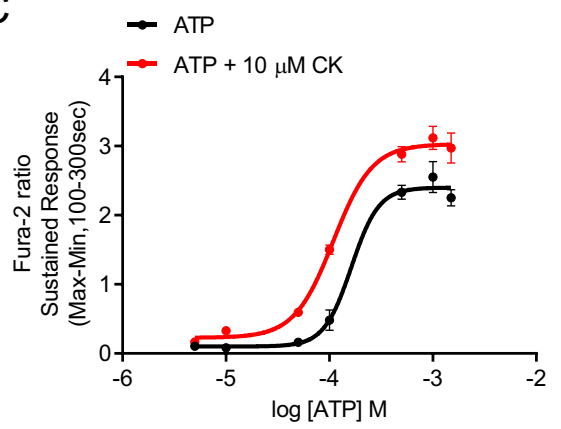

E
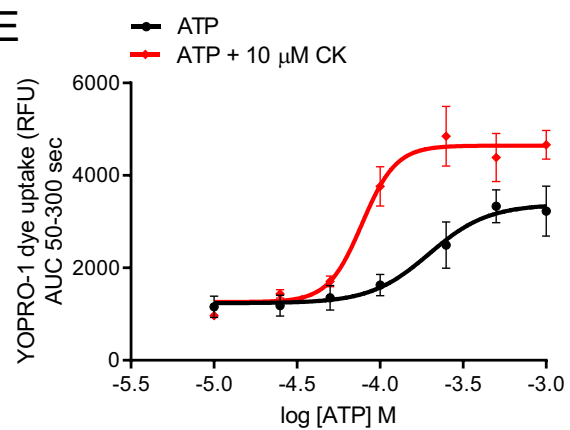

F

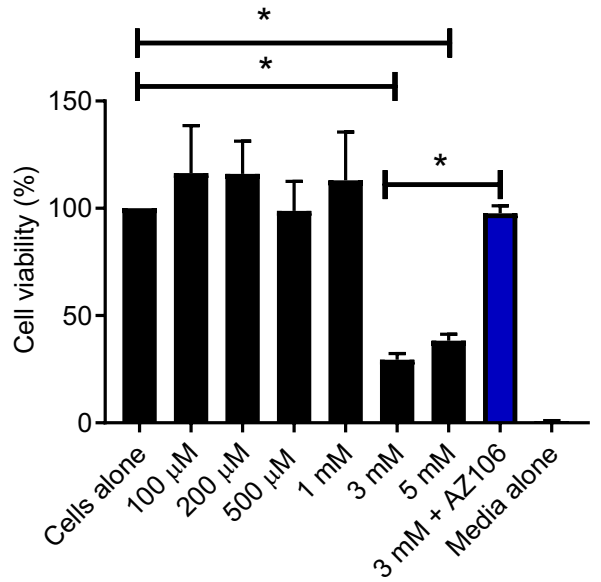

B

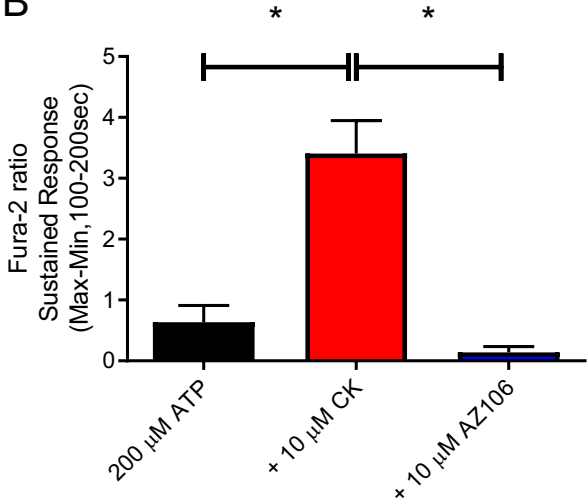

D

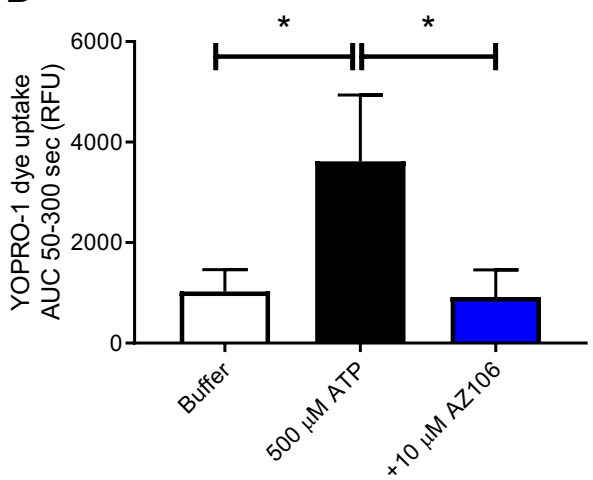

G

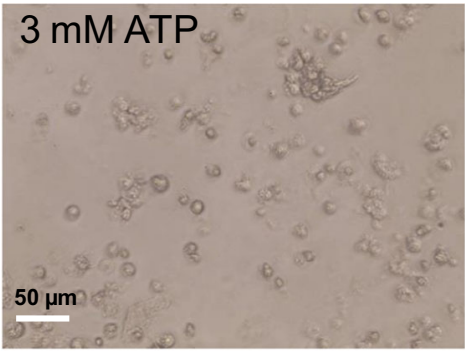

3 mM ATP + AZ106

Fig. 1 (See legend on next page.) 
(see figure on previous page)

Fig. 1 Compound K (CK) potentiates P2X7 responses. a J774 macrophages were stimulated with $200 \mu \mathrm{M}$ ATP in the presence or absence of CK or CK + AZ10606120 (both $10 \mu \mathrm{M})$ and $\mathrm{Ca}^{2+}$-responses were quantified using Fura-2. b The sustained response (100-200 sec) was quantified as an indicator of P2X7-dependent responses. c 3774 macrophages were stimulated with a range of ATP concentrations in the presence or absence of CK $(10 \mu \mathrm{M})$ prior to quantification of the Fura-2 sustained response as in $\mathbf{b}$. c $\mathrm{J774}$ macrophages were stimulated with $500 \mu \mathrm{M}$ ATP in the presence or absence of AZ10606120 (10 MM) to quantify uptake of YOPRO-1 dye. $\mathbf{d}$ YOPRO-1 dye uptake by $\mathrm{J774}$ macrophages to a range of ATP concentrations in the presence or absence of $\mathrm{CK}(10 \mu \mathrm{M})$. $\mathbf{f}$ Cell viability of $\mathrm{J} 774$ macrophages stimulated with a range of macrophages in the presence or absence of AZ10606120 (10 $\mu \mathrm{M})$ and quantified using AlamarBlue. $\mathbf{g}$ Light micrograph demonstrating the morphology of cells treated with $3 \mathrm{mM}$ ATP in the presence or absence of AZ10606120 $(10 \mu \mathrm{M})$. Experiments are representative of three independent experiments $(n=3)$. Error bars represent SD. Asterisks represent a significant difference $(p<0.05)$. Scale bars are $50 \mu \mathrm{m}$.

antagonism of P2X7 with a 43\% decrease (Fig. 4a, b). Three millimolar ATP also induced substantial caspase-3/ 7 activation after $24 \mathrm{~h}$ in a P2X7-dependent manner, although the percentage of positive cells was lower (76.3\%; Fig. $4 \mathrm{a}, \mathrm{b})$. CK alone $(10 \mu \mathrm{M})$ induced a small increase in caspase-3/7 activation but this was not significant when compared to ATP or the vehicle control (Fig. 4a, b). We observed that cell nuclei were condensing following treatment with ATP + CK comparable to the effect of staurosporine, suggesting that cells might be undergoing classical apoptosis (Fig. 4a). Nuclei area was quantified using Fiji software (ImageJ) and ATP + CK treated cells showed a 3-fold reduction (Fig. 4c). In contrast, nuclear condensation was not observed following stimulation with 3 mM ATP (Fig. 4c).

Treatment of cells with ATP + CK not only maximised caspase-3/7 activation, it also significantly accelerated caspase-3/7 activation kinetics measured using a NucView-488 caspase-3/7 assay. Treatments with ATP alone, DMSO, $3 \mathrm{mM}$ ATP, and staurosporine resulted in $<15 \%$ caspase- $3 / 7$ activation in the first $8 \mathrm{~h}$ of stimulation (Fig. 4d). Conversely, ATP + CK stimulated caspase-3/7 activation within $30 \mathrm{~min}$ and led to almost $100 \%$ of cells becoming caspase-3/7-positive within $6 \mathrm{~h}$ (Fig. 4d). This effect was inhibited by AZ10606120 and CK itself did not elicit significant caspase-3/7 activation in this timeframe (Fig. 4d).

\section{CK can potentiate the generation of mitochondrial reactive oxygen species (mtROS) and loss of mitochondrial membrane potential}

Based on the rapid activation of caspase-3/7, cell shrinking and nuclei condensation, it would seem likely that the route of cell death induced by ATP + CK could be apoptotic. Apoptosis can be induced by a large number of extrinsic and intrinsic signals, including reactive nitrogen species, DNA damage, hypoxia, serum deprivation, and pathogenic challenge ${ }^{18}$. Moreover, the exposure to xenobiotics, such as pesticides, chemotherapeutic drugs, and phytochemicals, can trigger apoptosis, which are often mediated by reactive oxygen species (ROS $)^{19}$. We first quantified the production of cellular ROS in response to $\mathrm{P} 2 \mathrm{X} 7$ activation using the fluorescent indicator DCFDA. Here we observed that stimulating J774 macrophages with ATP + CK did not induce a significant increase in DCFDA fluorescence over 60 min compared to $3 \mathrm{mM}$ ATP or CK alone (Fig. 5a, b) whereas the positive control (hydrogen peroxide) enhanced cellular DCFDA fluorescence. ATP + CK and $3 \mathrm{mM}$ ATP-induced changes in DCFDA were not affected by AZ10606120 suggesting P2X7 does not contribute to cellular ROS production (Fig. $5 \mathrm{a}, \mathrm{b})$.

Mitochondrial ROS (mtROS) can stimulate an increase in mitochondrial membrane permeability, which allows the release of pro-apoptotic molecules such as cytochrome $\mathrm{c}$ and apoptosis-inducing factor into the cytosol. We therefore investigated changes in the production of mtROS and in mitochondrial membrane potential. mtROS was quantified over a 105 min stimulation period using mitoSOX and the combination of ATP + CK was capable of inducing an almost 4-fold increase in the production of mtROS compared to ATP alone (Fig. $5 \mathrm{c}, \mathrm{d}$ ). Unlike cellular ROS production, the potentiation of mtROS production by CK appeared to be predominantly regulated by $\mathrm{P} 2 \mathrm{X} 7$, as inhibition of $\mathrm{P} 2 \mathrm{X} 7$ reduced $\mathrm{mtROS}$ back to baseline values (Fig. 5c, d). Furthermore, akin to the caspase- $3 / 7$ observations, CK not only influenced the magnitude of mtROS generation, but also accelerated the production of mtROS (Fig. 5c). MtROS production was also induced by $3 \mathrm{mM}$ ATP, although the rate of production was delayed compared to ATP + CK (Fig. 5c, d).

Changes in mitochondrial membrane potential were quantified using TMRM. Following stimulation with $500 \mu \mathrm{M}$ ATP over $24 \mathrm{~h}$, a high level of mitochondrial fluorescence was observed, indicating that TMRM was being retained in mitochondria and the membrane potential remained intact (Fig. 5e, f). Conversely, addition of ATP + CK, $3 \mathrm{mM}$ ATP, or staurosporine resulted in a significant loss of TMRM fluorescence over time, indicating a loss of mitochondrial membrane potential (Fig. 5e, f). Mitochondrial membrane collapse by ATP + CK and $3 \mathrm{mM}$ ATP, could be completely inhibited by AZ10606120 (Fig. 5e, f). Kinetically, 3 mM ATP could induce loss of mitochondrial membrane potential faster 
A
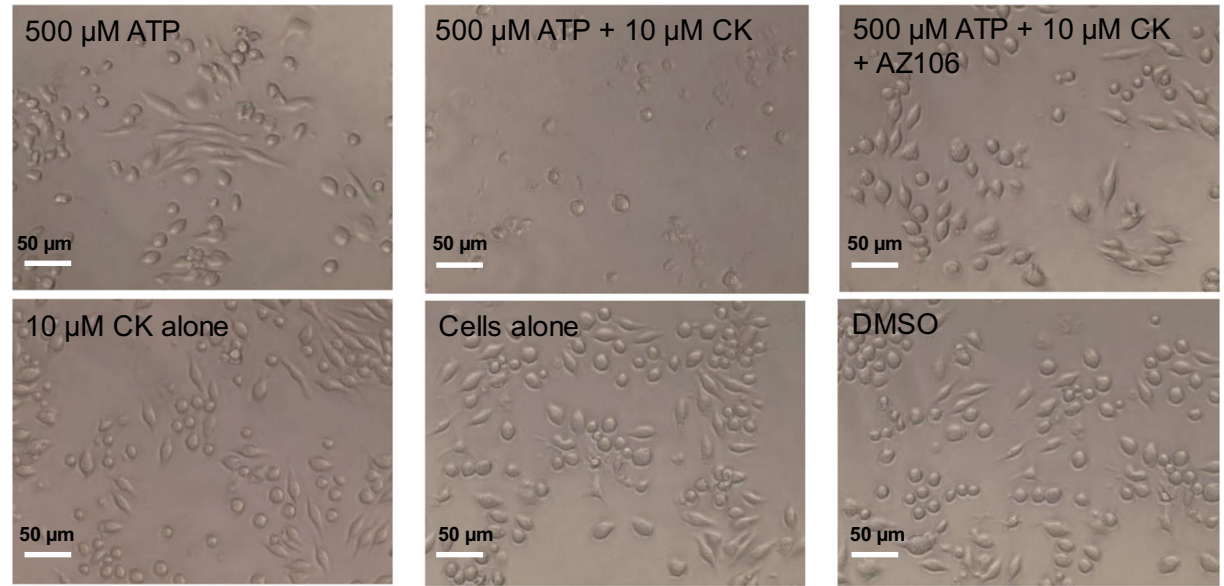

B

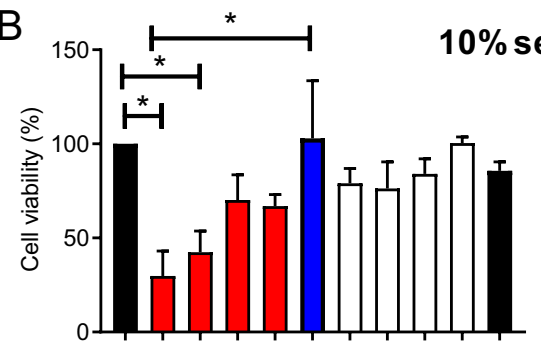

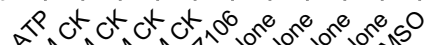

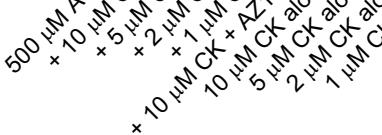

C
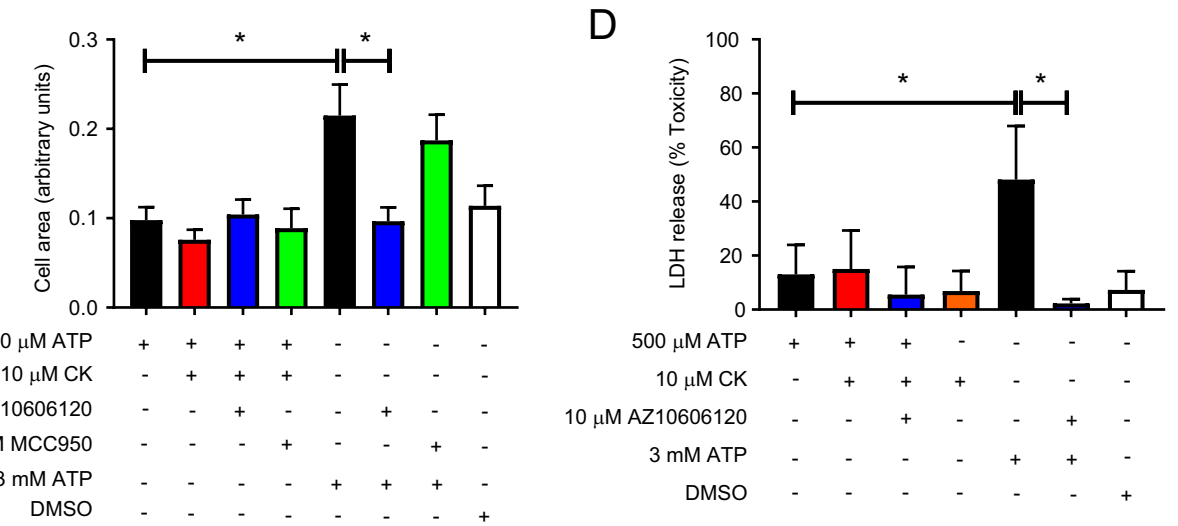

Fig. 2 CK potentiated cell death is morphologically different to death induced by 3 mM ATP. a Light micrographs of J774 cells stimulated with $500 \mu \mathrm{M}$ ATP alone or in the presence of various treatments (CK and AZ10606120 both $10 \mu \mathrm{M}$ ). b J774 cells were stimulated with decreasing concentrations of CK (10-1 $\mu \mathrm{M})$ in combination with $500 \mu \mathrm{M}$ ATP or alone. AZ10606120 was used at a concentration of $10 \mu \mathrm{M}$ and cell death quantified by AlamarBlue. c $\mathbf{J 7 7 4}$ cells were stimulated with various treatments and the area of the cells after $3 \mathrm{~h}$ was quantified using Fiji. $\mathbf{d}$ LDH release following a $6 \mathrm{~h}$ stimulation with various treatments. Experiments are representative of three independent experiments $(n=3)$. Error bars represent SD. Asterisks represent a significant difference $(p<0.05)$. Scale bars are $50 \mu \mathrm{m}$.

than ATP + CK, with $26.6 \%$ of cells losing membrane potential compared to $3.6 \%$ after $2 \mathrm{~h}$ stimulation, respectively. By $4 \mathrm{~h}$ the percentage of cells losing membrane potential increased to $58.1 \%$ and $68 \%$ for ATP + CK and $3 \mathrm{mM}$ ATP, respectively. After $24 \mathrm{~h}$, the loss of membrane potential between the two were comparable with $86.4 \%$ 

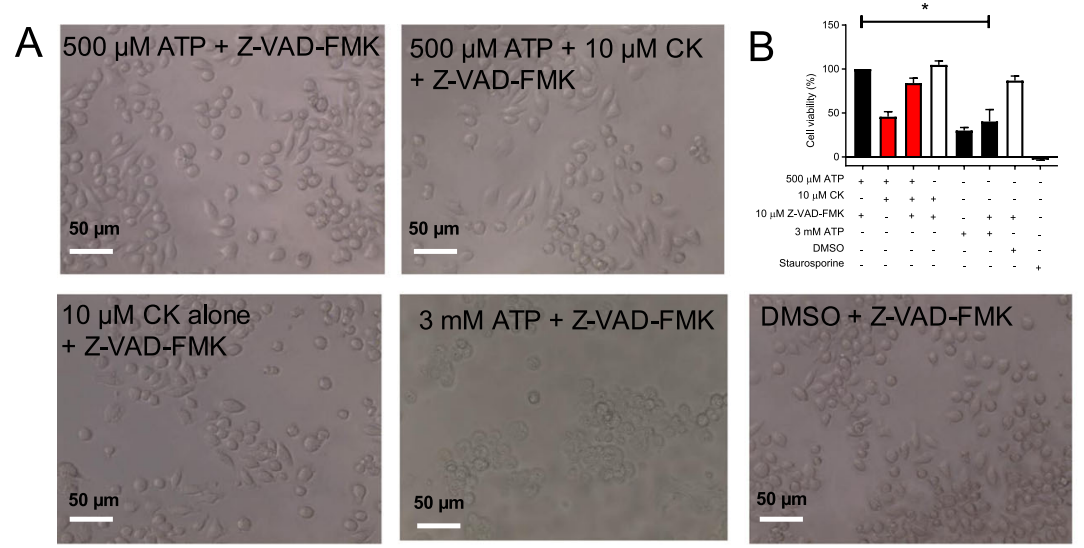

C

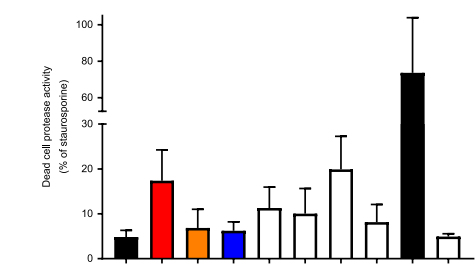

D

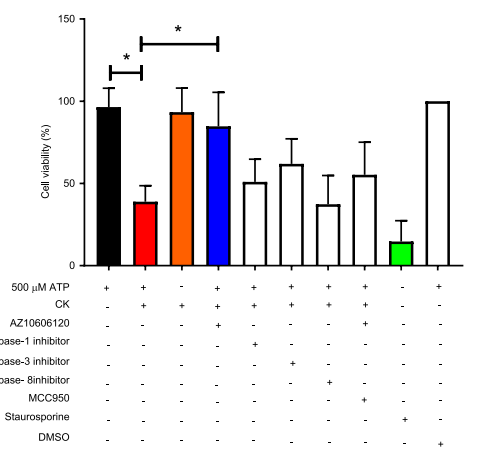

$\mathrm{E}$

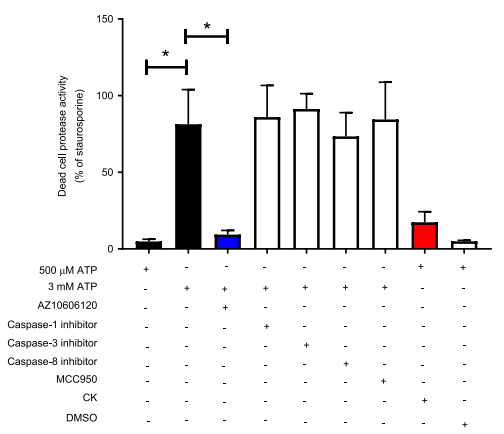

$\mathrm{F}$
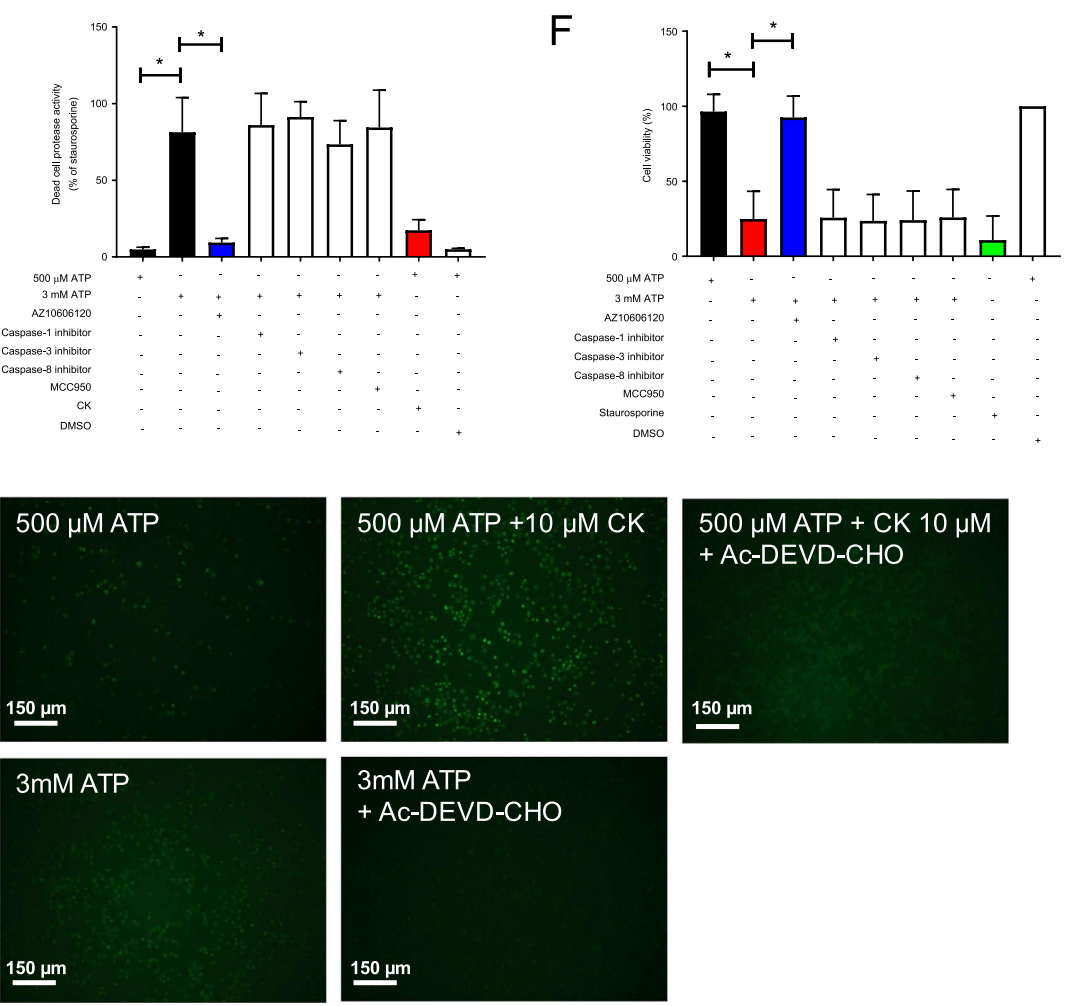

Fig. 3 (See legend on next page.) 
(see figure on previous page)

Fig. 3 CK promotes cell death in a caspase-dependent manner but death induced by $3 \mathrm{mM}$ ATP could not be blocked by caspase inhibitors. a Light micrographs depicting $\mathrm{J774}$ cells pre-incubated with the pan-caspase inhibitor Z-VAD-FMK (10 $\mu$ M) prior to stimulation with $500 \mu \mathrm{M}$ ATP, $500 \mu \mathrm{M}$ ATP + CK, CK alone, or 3 mM ATP. b Cell viability of J774 cells stimulated with the treatments outlined in a. c J774 cells were pre-

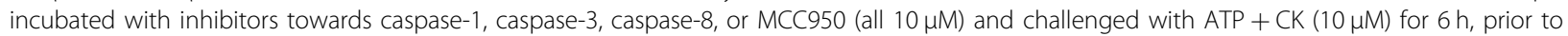
quantification of a protease released by dead cells. $\mathbf{d}$ J774 cells were pre-incubated with inhibitors towards caspase-1, caspase-3, caspase-8, or MCC950 (all $10 \mu \mathrm{M})$ and challenged with ATP + CK $(10 \mu \mathrm{M})$ for $24 \mathrm{~h}$, prior to quantification of cell death by Alamar Blue. e J774 cells were preincubated with inhibitors towards caspase-1, caspase-3, caspase-8, or MCC950 (all $10 \mu \mathrm{M}$ ) and challenged with $3 \mathrm{mM}$ ATP for $6 \mathrm{~h}$, prior to quantification of a protease released by dead cells. f $\mathrm{J} 774$ cells were pre-incubated with inhibitors towards caspase-1, caspase-3, caspase-8, or MCC950 (all $10 \mu \mathrm{M})$ and challenged with $3 \mathrm{mM}$ ATP for $24 \mathrm{~h}$, prior to quantification of cell death by Alamar Blue. g Fluorescent micrographs of J774 cells stimulated for $24 \mathrm{~h}$ with various treatments in the presence or absence of the caspase-3/7 inhibitor Ac-DEVD-CHO (10 $\mu \mathrm{M})$. Caspase-3/7 activation was quantified using an EarlyTox ${ }^{\mathrm{TM}}$ Caspase-3/7 NucView 488 kit. Experiments are representative of three independent experiments $(n=3)$. Error bars represent SD. Asterisks represent a significant difference $(p<0.05)$.

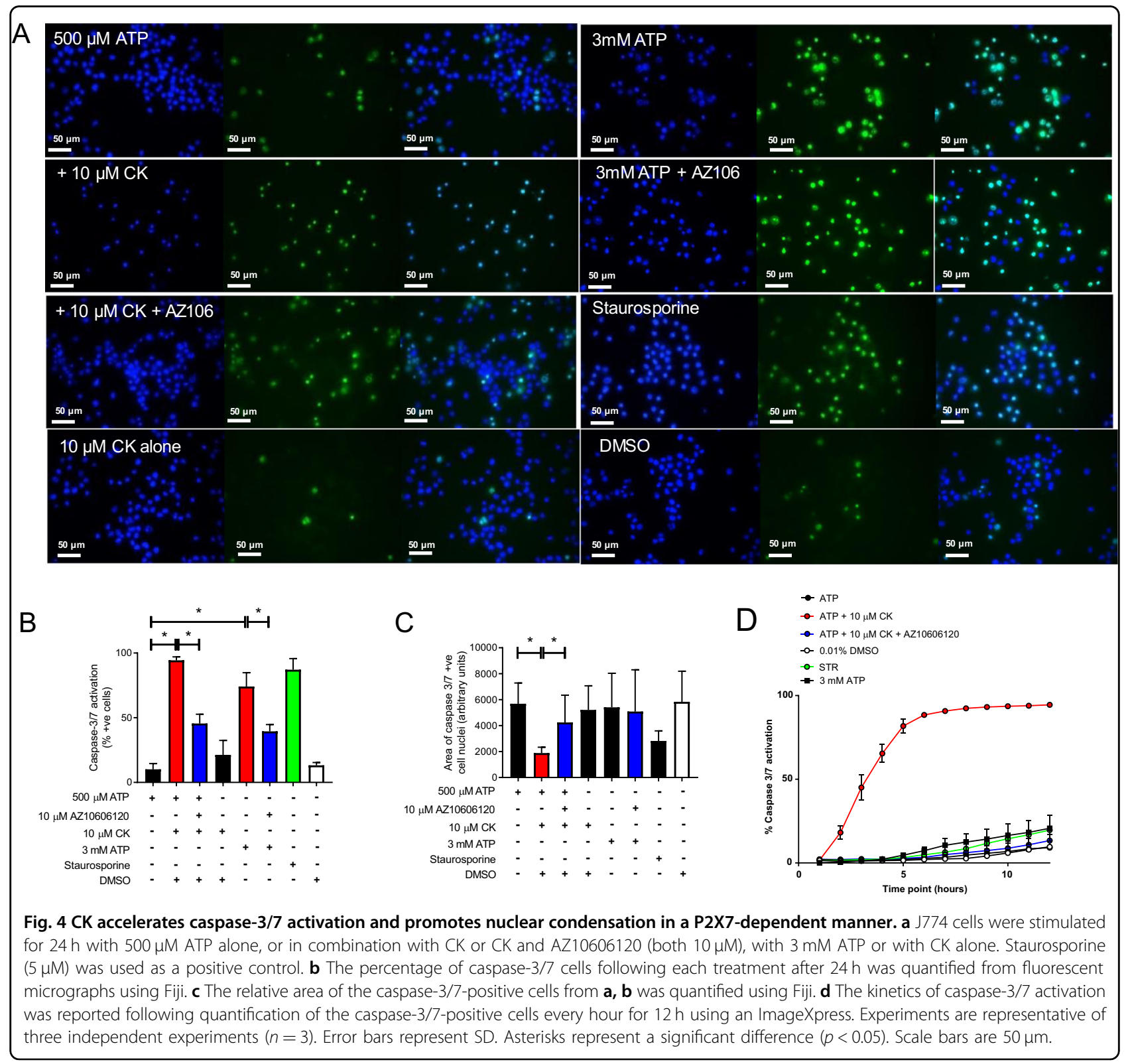




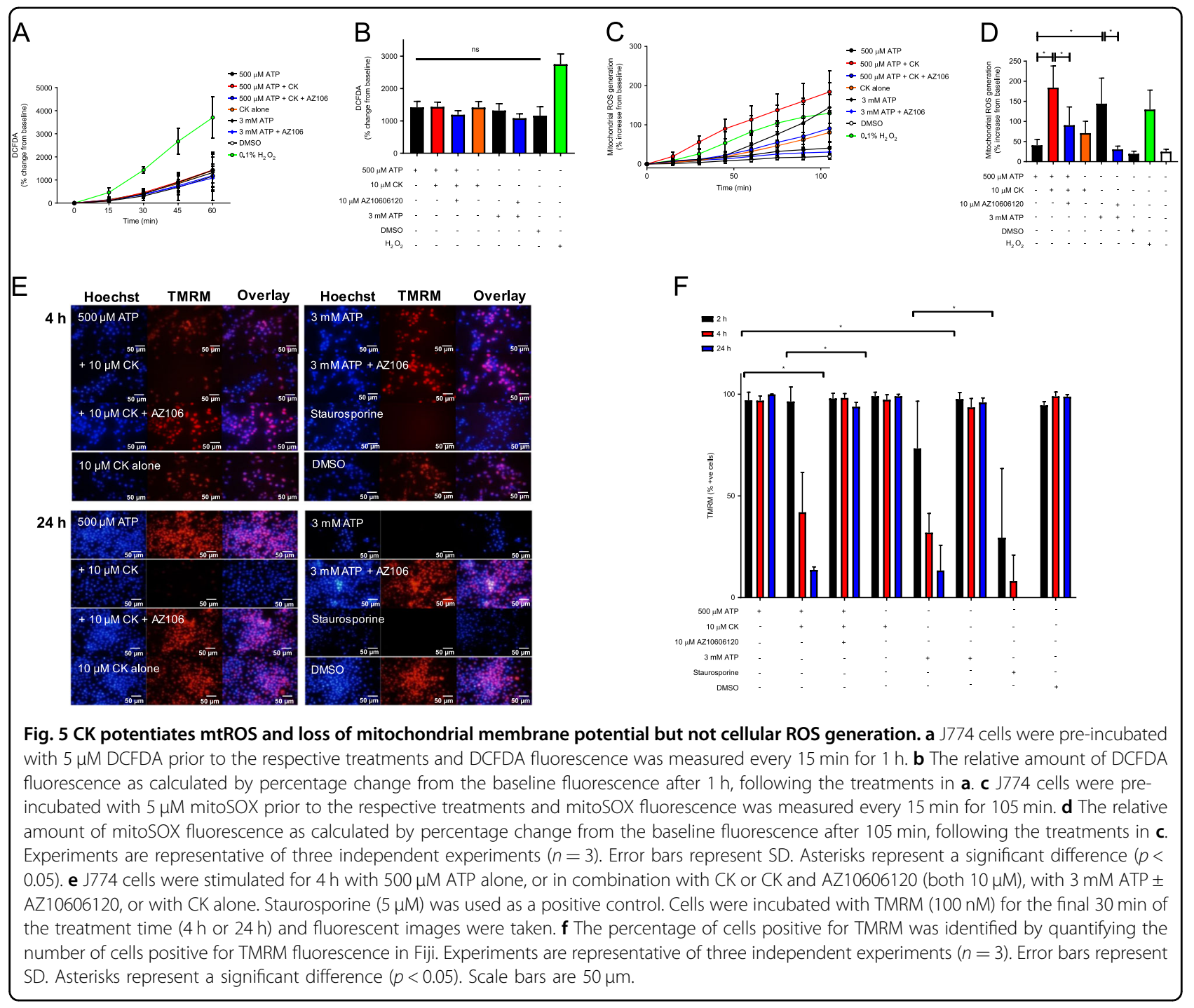

and $86.7 \%$ of cells losing membrane potential following stimulation with ATP + CK or $3 \mathrm{mM}$ ATP, respectively (Fig. 5f).

Cell death and loss of mitochondrial membrane potential induced by ATP + CK can be reduced by inhibiting Bax and scavenging $\mathrm{mtROS}$

We explored the mechanisms underlying mtROS generation and the loss of mitochondrial membrane potential correlated with differential cell death outcomes following P2X7 activation using mitoTEMPO as a scavenger of mtROS and a Bax inhibitory peptide to prevent Bax activation. After a $6 \mathrm{~h}$ incubation with ATP $+\mathrm{CK}$, cell death could be completely inhibited by mitoTEMPO or the Bax inhibitory peptide (Fig. 6a). Over prolonged stimulations, mitoTEMPO could inhibit cell death to a similar level as AZ10606120, suggesting that mtROS was one of the early triggers of cell death under these conditions. However, the Bax inhibitor could not inhibit cell death as effectively after $24 \mathrm{~h}$ of stimulation (Fig. 6b). Conversely, neither mitoTEMPO nor the Bax inhibitory peptide could inhibit cell death induced by $3 \mathrm{mM}$ ATP following either a $6 \mathrm{~h}$ or $24 \mathrm{~h}$ stimulation (Fig. 6c, d). These observations were also extended to mitochondrial membrane potential. Following $4 \mathrm{~h}$ of stimulation with ATP + CK, $\sim 50 \%$ of cells had completely lost mitochondrial membrane potential (no TMRM fluorescence) and this was inhibited by mitoTEMPO and inhibition of Bax (Fig. 6e, f). Neither mitoTEMPO nor Bax inhibitory peptide could inhibit the loss of mitochondrial membrane potential elicited by $3 \mathrm{mM}$ ATP (Fig. $6 \mathrm{~g}$, h).

\section{P2X7 stimulated increases in mitochondrial $\mathrm{Ca}^{2+}$ contribute to $\mathrm{mtROS}$ production and cell death}

$\mathrm{Ca}^{2+}$ plays an important role in regulating numerous biological processes, including the induction of mtROS. 


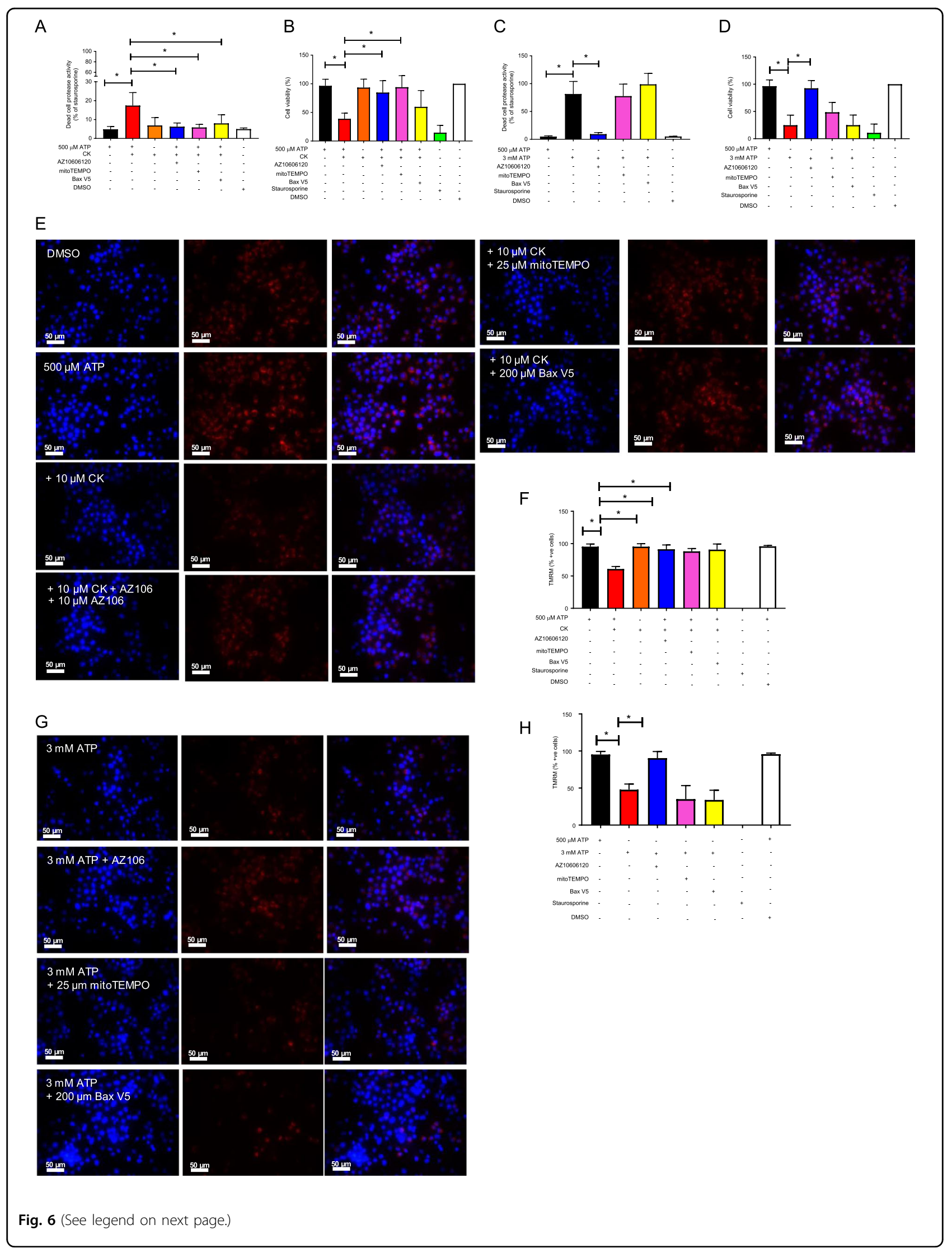


(see figure on previous page)

Fig. 6 Scavenging mtROS or inhibiting Bax can prevent cell death and loss of mitochondrial membrane potential following stimulation with ATP + CK but not by $\mathbf{3}$ mM ATP. a J774 cells were pre-incubated with the mtROS scavenger mitoTEMPO ( $25 \mu \mathrm{M})$ or the Bax V5 inhibitor peptide $(200 \mu \mathrm{M})$ and challenged with ATP + CK $(10 \mu \mathrm{M})$ for $6 \mathrm{~h}$, prior to quantification of a protease released by dead cells. $\mathbf{b}$ or a $24 \mathrm{~h}$ stimulation prior to quantification of cell death by AlamarBlue. c J774 cells were pre-incubated with the mtROS scavenger mitoTEMPO or the Bax V5 inhibitor peptide and challenged with $3 \mathrm{mM}$ ATP for $6 \mathrm{~h}$, prior to quantification of a protease released by dead cells. $\mathbf{d}$ or a $24 \mathrm{~h}$ stimulation prior to quantification of cell death by by AlamarBlue. e Fluorescent micrographs of $\mathrm{J774}$ cells pre-incubated with the mtROS scavenger mitoTEMPO or the Bax V5 inhibitor peptide and challenged with ATP + CK for $4 \mathrm{~h}$, prior to incubation with TMRM (100 nM) for the final 30 min of the treatment time to measure mitochondrial membrane potential. $\mathbf{f}$ The percentage of cells positive for TMRM after stimulation with ATP + CK was identified by quantifying the number of cells positive for TMRM fluorescence in Fiji. $\mathbf{g}$ Fluorescent micrographs of J774 cells pre-incubated with the mtROS scavenger mitoTEMPO or the Bax V5 inhibitor peptide and challenged with $3 \mathrm{mM}$ ATP for $4 \mathrm{~h}$, prior to incubation with TMRM (100 nM) for the final 30 min of the treatment time to measure mitochondrial membrane potential. $\mathbf{h}$ The percentage of cells positive for TMRM after stimulation with $3 \mathrm{mM}$ ATP was identified by quantifying the number of cells positive for TMRM fluorescence in Fiji. Experiments are representative of three independent experiments $(n=3)$. Error bars represent SD. Asterisks represent a significant difference $(p<0.05)$. Scale bars are $50 \mu m$.

Therefore, we investigated the effect of $\mathrm{Ca}^{2+}$ influx on the generation of mtROS and mechanism of cell death. We first measured the total inward movement of charged ions (depolarisation) across the plasma membrane of J774 cells following stimulation of P2X7 with ATP + CK by utilising a cellular membrane potential kit. Activation of P2X7 by ATP + CK or $3 \mathrm{mM}$ ATP evoked a large membrane depolarisation due to the inward flux of cations through open P2X7 channels (Fig. 7a). Measuring the first $180 \mathrm{sec}$ of P2X7 activation revealed a larger depolarisation response amplitude to $3 \mathrm{mM}$ ATP than to ATP $+\mathrm{CK}$ (Fig. $7 \mathrm{~b})$. Continued measurement of plasma membrane potential over $90 \mathrm{~min}$ revealed that the ATP + CK response was significantly shorter in duration than the $3 \mathrm{mM}$ ATP-induced response with the mean time taken to fall from $90 \%$ to $10 \%$ response being $1820 \mathrm{sec}$ (30.3 min) compared with $3740 \mathrm{sec}(62.3 \mathrm{~min})$ for $3 \mathrm{mM}$ ATP (Fig. 7a, c). However, specifically measuring intracellular $\mathrm{Ca}^{2+}$ concentrations in cytosolic and mitochondrial compartments with Fluo-4 and Rhod-2 $\mathrm{Ca}^{2+}$ indicator dyes, respectively, identified that the cytosolic elevations in $\mathrm{Ca}^{2+}$ and mitochondrial uptake were significantly greater following the application of ATP + CK compared to $3 \mathrm{mM}$ ATP (Fig. $7 \mathrm{~d}-\mathrm{i}$ ). Continued measurement of $\mathrm{Ca}^{2+}$ elevations in cytosol and mitochondria over $90 \mathrm{~min}$ revealed larger and more sustained elevations in $\mathrm{Ca}^{2+}$ with ATP + CK (Fig. 7c-i).

Enhanced mitochondrial $\mathrm{Ca}^{2+}$ can be a trigger to produce mtROS, and mtROS appeared to be the trigger for cell death induced by positive modulation of P2X7. Chelation of extracellular $\mathrm{Ca}^{2+}$ using EGTA resulted in both a decreased and delayed induction of mtROS by ATP + CK but did not affect the slower production of mtROS following stimulation with $3 \mathrm{mM}$ ATP (Fig. 7j). Focusing on data obtained at the $30 \mathrm{~min}$ time-point showed that removing $\mathrm{Ca}^{2+}$ could significantly abrogate the quick onset of mtROS generation by ATP + CK but not $3 \mathrm{mM}$ ATP (Fig. 7k). Chelating extracellular $\mathrm{Ca}^{2+}$ could significantly inhibit the cell death induced by $3 \mathrm{mM}$ ATP, but inhibited the cell death induced by ATP $+\mathrm{CK}$ to a greater extent after $6 \mathrm{~h}$ suggesting that $\mathrm{Ca}^{2+}$ plays a critical role in CK-potentiated apoptosis (Fig. $7 \mathrm{~m}$ ).

\section{Discussion}

Our study focused on understanding the mechanism of cell death induced following positive allosteric modulation of the ATP-gated ion channel, P2X7. As a result, we demonstrated several findings. Notably, high millimolar ATP concentrations stimulated an unregulated form of cell death, which could not be stopped by inhibiting caspases, blocking Bax, or by scavenging mtROS, and was characterised by early cell swelling and cell lysis. Conversely, the combination of ATP and CK induced a significant increase in mitochondrial $\mathrm{Ca}^{2+}$, which was accompanied by accelerated mtROS production, accelerated caspase-3/7 activation, and cell death that can be partly inhibited by caspase inhibitors, inhibition of Bax, removal of extracellular $\mathrm{Ca}^{2+}$, or mtROS scavenging (Fig. 8).

Maximal ATP (3 mM) could elicit a large movement of charged ions (depolarisation) but CK-induced potentiation of P2X7 appeared to selectively increase $\mathrm{Ca}^{2+}$ influx and intracellular $\mathrm{Ca}^{2+}$ concentrations, notably enhancing mitochondrial $\mathrm{Ca}^{2+}$. We have previously reported in detail that $\mathrm{CK}$ can act as a positive allosteric modulator of P2X7 receptors ${ }^{15,16}$. Utilising a molecular modelling and mutagenesis approach we recently identified an allosteric pocket within the central vestibule of P2X7. However, it is still currently poorly understood how binding to this novel binding pocket enhances ion channel activity, macropore formation, or how CK modulates ion permeability ${ }^{15,16}$.

It is well established that $\mathrm{P} 2 \mathrm{X} 7$ can participate in the regulation of cell death, with high concentrations of ATP inducing necrotic, pyroptotic, or apoptotic cell death depending on the stimulatory factors present, the incubation time, and the cell type ${ }^{3,11,20,21}$. Previous reports state that P2X7 activation stimulates cell death in J774 macrophages via colloido-osmotic lysis, characterised by 


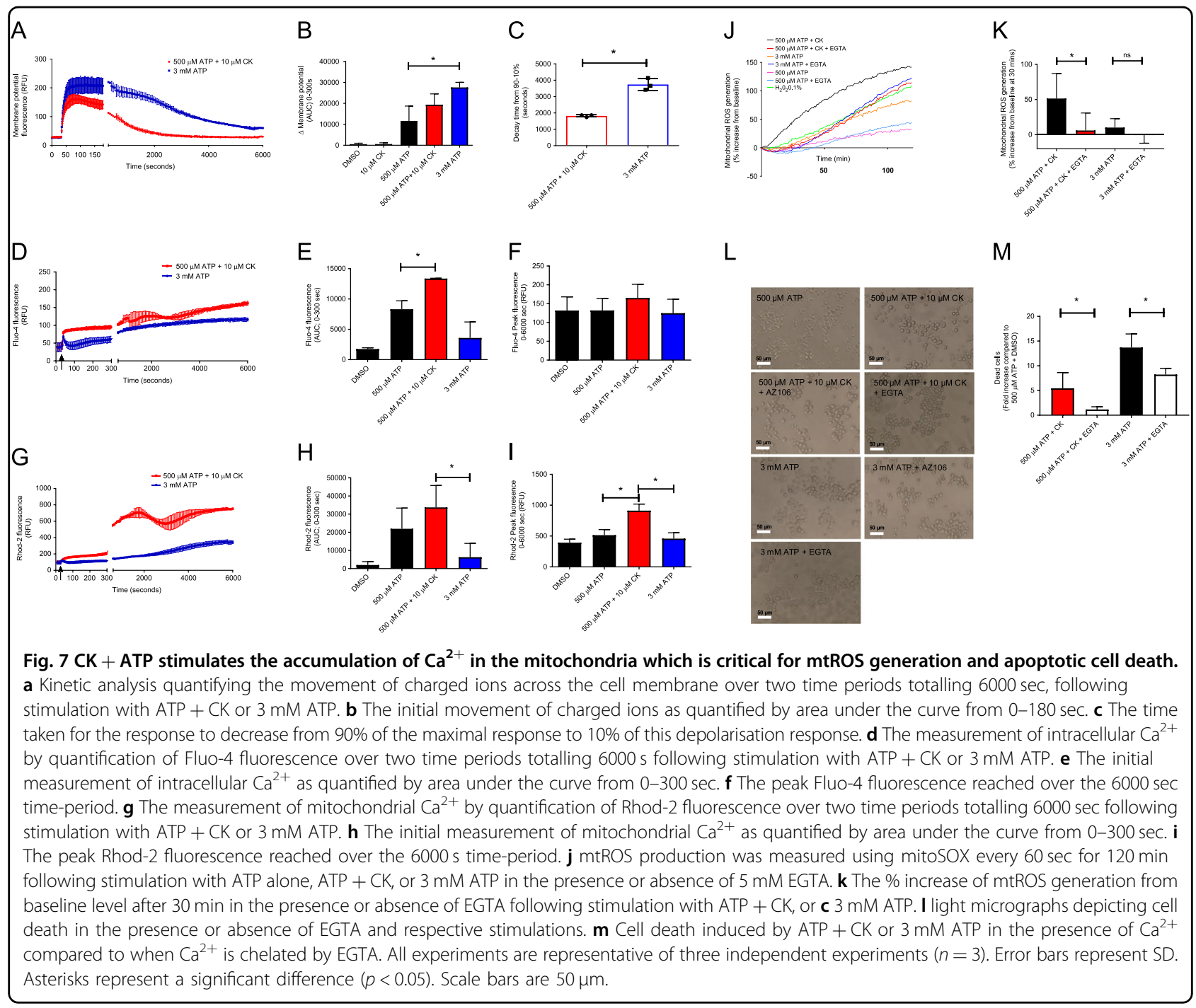

cell swelling and rupture ${ }^{17}$. Concordant with these observations, J774 cells treated with $3 \mathrm{mM}$ ATP swelled to almost twice the size and appeared to rupture, based on the detection of LDH in the cell supernatant. Moreover, this lytic cell death could not be inhibited by caspase inhibitors, mtROS scavenging, or Bax inhibition. However, chelation of extracellular $\mathrm{Ca}^{2+}$ could prevent some of the cell death induced by $3 \mathrm{mM}$ ATP, which suggests the large movement of ions and divergence from the osmotic equilibrium are likely key contributors to this form of cell death.

Conversely, the fast increase in mitochondrial $\mathrm{Ca}^{2+}$ and subsequent production of mtROS seem to be critical triggers in the induction of cell death following stimulation with ATP + CK. The accelerated kinetics of mtROS are correlated with caspase-3/7 activation and likely occurs because of the loss of mitochondrial membrane integrity induced by mtROS or via release of pro- apoptotic factors through Bax channels. Moreover, this form of cell death was caspase-dependent, and the pancaspase inhibitor could limit cell death. Inhibition of individual caspases had less of an effect but the NLRP3 inflammasome, caspase- 1 , and caspase- 3 were implicated. MtROS production is linked to activation of the NLRP3 inflammasome ${ }^{22}$, and caspase- 1 has recently been identified to activate caspase- $3^{23}$. Additional activation of caspase- 3 by caspase- 1 could explain why activation of caspase-3/7 was so significantly accelerated, but this is something that would need to be explored further.

There is growing evidence that ROS and mitochondria play an important role in stimulating apoptosis, whilst mitochondria are also both a target and source of $\operatorname{ROS}^{19}$. P2X7 activation has been implicated in the generation of ROS in macrophages and microglia, which could be inhibited by P2X7 antagonists including oxidized ATP, Brilliant Blue G, and AZ10606120 $0^{5,24,25}$. In contrast to 


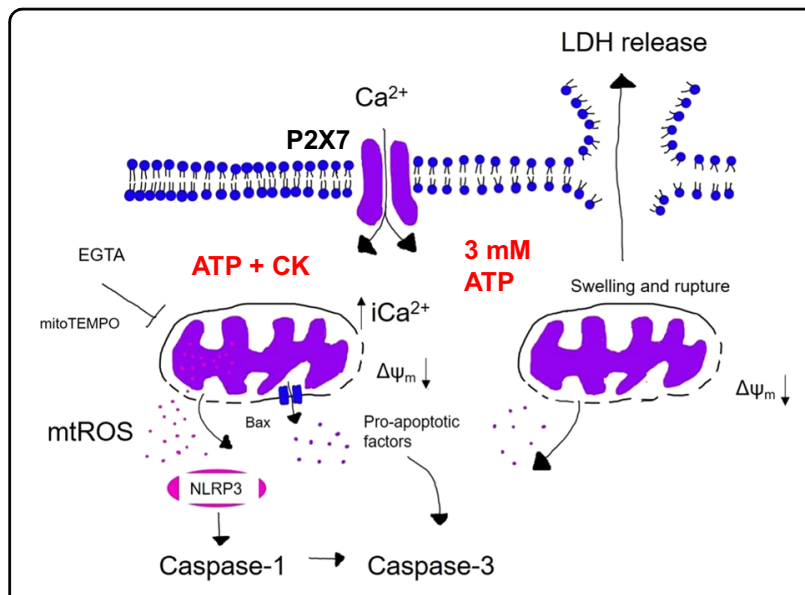

Fig. 8 Summary of P2X7-dependent signals eliciting different cell death responses. Upon stimulation with $3 \mathrm{mM}$ ATP, J774 cells die in a caspase-independent manner. Here, the movement of charged ions into the cell disrupts the osmotic equilibrium and cells begin to swell. This leads to loss of mitochondrial membrane potential and membrane rupture, releasing LDH to the extracellular milieu. Cells that have not ruptured then become caspase-3/7-positive. However, stimulation with ATP + CK results in an increase in mitochondrial $\mathrm{Ca}^{2+}$ that stimulates the production of $\mathrm{mtROS}$. This results in cell death that is both dependent upon Bax and caspase activation. This cell death could also be inhibited by scavenging mtROS or chelating $\mathrm{Ca}^{2+}$ using mitoTEMPO or EGTA, respectively. In this instance, it could be possible that mtROS might interact with the NLRP3 inflammasome and activate caspase- 1 , which in turn might cleave caspase-3 and explain the significantly accelerated caspase-3/7 activation observed following stimulation with ATP + CK.

cellular ROS, P2X7 activation and $\mathrm{Ca}^{2+}$ were critical in the generation of mtROS following stimulation with ATP and CK. Notably, ATP and CK could stimulate an instant spike in mtROS production and upon removal of $\mathrm{Ca}^{2+}$ or inhibition of P2X7, this initial spike was lost, and cells survived.

ROS initiate the intrinsic pathway of mitochondria and promote the activation of pro-apoptotic proteins ${ }^{26-28}$. An increase in the production of mtROS, particularly by hydrogen peroxide, has previously been directly linked with collapse of mitochondrial membrane potential ${ }^{29-31}$. P2X7 has been implicated in stimulating mitochondrial dysfunction and membrane collapse in response to large increases in intracellular $\mathrm{Ca}^{2+}$ accumulation. The subsequent loss of mitochondrial membrane potential and increase in mitochondrial membrane permeability has been implicated in the release of numerous pro-apoptotic factors such as apoptosis-inducing factor and cytochrome c, which contributes to formation of the apoptosome complex, activation of caspase-3, and ultimately apopto$\mathrm{sis}^{32-34}$. Therefore, by reducing the amount of $\mathrm{Ca}^{2+}$ available to enter the cell, we have limited the ability of ATP and CK to promote the steps necessary to evoke early mtROS production, thus removing the initial trigger and the ability of CK to promote cell death.

To conclude, CK potentiation of P2X7-dependent responses promotes the induction of the intrinsic pathway of apoptosis via an increase in mitochondrial $\mathrm{Ca}^{2+}$, accelerated production of mtROS, loss of mitochondrial membrane potential, and accelerated caspase-3/7 activation while activation with high ATP concentrations induces an early caspase-independent lytic cell death pathway. This provides evidence that allosteric modulation of P2X7 can be exploited to calibrate cell death outcomes. Positive allosteric modulation of P2X7 receptors opens various avenues of exploration; such as whether it can enhance the killing of intracellular pathogens, augment the removal of P2X7 expressing cancer cells, or contribute to the resolution of inflammation.

\section{Acknowledgements}

We thank the Biomedical Research Centre, University of East Anglia for use of the Cytoflex flow cytometer. This study was supported by a BBSRC project grant to LS (BB/N018427/1). K.D. was supported by a RMIT University PhD scholarship (2014-2018).

\section{Data availability}

Data are available upon reasonable request to the corresponding author.

Conflict of interest

The authors decalre that they have no conflict of interest.

\section{Publisher's note}

Springer Nature remains neutral with regard to jurisdictional claims in published maps and institutional affiliations.

Supplementary Information accompanies this paper at (https://doi.org/ 10.1038/s41419-019-2110-3).

Received: 3 June 2019 Revised: 15 October 2019 Accepted: 25 October 2019

Published online: 25 November 2019

\section{References}

1. Di Virgilio, F., Dal Ben, D., Sarti, A. C., Giuliani, A. L. \& Falzoni, S. The P2X7 Receptor in Infection and Inflammation. Immunity 47, 15-31 (2017).

2. Orioli, E., De Marchi, E., Giuliani, A. L. \& Adinolfi, E. P2X7 receptor orchestrates multiple signalling pathways triggering inflammation, autophagy and metabolic/trophic responses. Curr. Medicinal Chem. 24, 2261-2275 (2017).

3. Mackenzie, A. B., Young, M. T., Adinolfi, E. \& Surprenant, A. Pseudoapoptosis induced by brief activation of ATP-gated P2X7 receptors. J. Biol. Chem. 280, 33968-33976 (2005).

4. Kong, Q. et al. P2X(7) nucleotide receptors mediate caspase-8/9/3dependent apoptosis in rat primary cortical neurons. Purinergic Sig. 1, 337-347 (2005).

5. Bartlett, R., Yerbury, J. J. \& Sluyter, R. P2X7 receptor activation induces reactive oxygen species formation and cell death in murine EOC13 microglia. Mediators Inflamm. 2013, 271813 (2013).

6. Nishida, $K$. et al. Mitochondrial dysfunction is involved in P2X7 receptormediated neuronal cell death. J. Neurochem. 122, 1118-1128 (2012).

7. Sakaki, H. et al. P2X4 receptor regulates $\mathrm{P} 2 \mathrm{X} 7$ receptor-dependent IL-1beta and $\mathrm{IL}-18$ release in mouse bone marrow-derived dendritic cells. Biochem. Biophys. Res Commun. 432, 406-411 (2013).

8. Shieh, C. H., Heinrich, A., Serchov, T., van Calker, D. \& Biber, K. P2X7-dependent, but differentially regulated release of $I L-6, C C L 2$, and TNF-alpha in cultured mouse microglia. Glia 62, 592-607 (2014). 
9. Mehta, V. B., Hart, J. \& Wewers, M. D. ATP-stimulated release of interleukin (IL)1 beta and IL-18 requires priming by lipopolysaccharide and is independent of caspase-1 cleavage. J. Biol. Chem. 276, 3820-3826 (2001).

10. Piccini, A. et al. ATP is released by monocytes stimulated with pathogensensing receptor ligands and induces $\mathrm{IL}-1$ beta and $\mathrm{IL}-18$ secretion in an autocrine way. Proc. Natl Acad. Sci. USA 105, 8067-8072 (2008).

11. Yang, D., He, Y., Munoz-Planillo, R., Liu, Q. \& Nunez, G. Caspase-11 requires the pannexin-1 channel and the purinergic P2X7 pore to mediate pyroptosis and endotoxic shock. Immunity 43, 923-932 (2015).

12. Fernando, S. L. et al. A polymorphism in the $P 2 X 7$ gene increases susceptibility to extrapulmonary tuberculosis. Am. J. Respir. Crit. Care Med. 175, 360-366 (2007).

13. Ghiringhelli, F., Bruchard, M., Chalmin, F. \& Rebe, C. Production of adenosine by ectonucleotidases: a key factor in tumor immunoescape. J. Biomedicine Biotechnol. 2012, 473712 (2012).

14. Finlay, B. B. \& McFadden, G. Anti-immunology: evasion of the host immune system by bacterial and viral pathogens. Cell 124, 767-782 (2006).

15. Helliwell, R. M. et al. Selected ginsenosides of the protopanaxdiol series are novel positive allosteric modulators of P2X7 receptors. Br. J. Pharm. 172, 3326-3340 (2015).

16. Bidula, S. M., Cromer, B. A., Walpole, S., Angulo, J. \& Stokes, L. Mapping a novel positive allosteric modulator binding site in the central vestibule region of human P2X7. Sci. Rep. 9, 3231 (2019).

17. Murgia, M., Pizzo, P., Steinberg, T. H. \& Di Virgilio, F. Characterization of the cytotoxic effect of extracellular ATP in J774 mouse macrophages. Biochem. J. 288(Pt 3), 897-901 (1992).

18. Elmore, S. Apoptosis: a review of programmed cell death. Toxicol. Pathol. $\mathbf{3 5}$ 495-516 (2007).

19. Redza-Dutordoir, M. \& Averill-Bates, D. A. Activation of apoptosis signalling pathways by reactive oxygen species. Biochim. Biophys. Acta 1863, 2977-2992 (2016).

20. Dagvadorj, J. et al. Lipopolysaccharide induces alveolar macrophage necrosis via CD14 and the $\mathrm{P} 2 \mathrm{X} 7$ receptor leading to interleukin-1alpha release. Immunity 42, 640-653 (2015).

21. Hanley, $P$. J. et al. Transient $P 2 X 7$ receptor activation triggers macrophage death independent of Toll-like receptors 2 and 4, caspase-1, and pannexin-1 proteins. J. Biol. Chem. 287, 10650-10663 (2012).
22. Heid, M. E. et al. Mitochondrial reactive oxygen species induces NLRP3 dependent lysosomal damage and inflammasome activation. J. Immunol. 191, 5230 (2013)

23. Taabazuing, C. Y., Okondo, M. C. \& Bachovchin, D. A. Pyroptosis and apoptosis pathways engage in bidirectional crosstalk in monocytes and macrophages. Cell Chem. Biol. 24, 507-514.e504 (2017).

24. Parvathenani, L. K. et al. P2X7 mediates superoxide production in primary microglia and is up-regulated in a transgenic mouse model of Alzheimer's disease. J. Biol. Chem. 278, 13309-13317 (2003).

25. Pfeiffer, Z. A. et al. Nucleotide receptor signaling in murine macrophages is linked to reactive oxygen species generation. Free Radic. Biol. Med. 42, 1506-1516 (2007).

26. Wu, C. C. \& Bratton, S. B. Regulation of the intrinsic apoptosis pathway by reactive oxygen species. Antioxid. Redox Signal 19, 546-558 (2013).

27. Yoshida, K. \& Miki, Y. The cell death machinery governed by the p53 tumor suppressor in response to DNA damage. Cancer Sci. 101, 831-835 (2010).

28. Luna-Vargas, M. P. \& Chipuk, J. E. The deadly landscape of pro-apoptotic BCL-2 proteins in the outer mitochondrial membrane. FEBS J. 283, 2676-2689 (2016).

29. Szigeti, A. et al. Facilitation of mitochondrial outer and inner membrane permeabilization and cell death in oxidative stress by a novel $\mathrm{BCl}-2$ homology 3 domain protein. J. Biol. Chem. 285, 2140-2151 (2010).

30. Tada-Oikawa, S., Oikawa, S., Kawanishi, M., Yamada, M. \& Kawanishi, S. Generation of hydrogen peroxide precedes loss of mitochondrial membrane potential during DNA alkylation-induced apoptosis. FEBS Lett. 442, 65-69 (1999).

31. Maechler, P., Jornot, L. \& Wollheim, C. B. Hydrogen peroxide alters mitochondrial activation and insulin secretion in pancreatic beta cells. J. Biol. Chem. 274, 27905-27913 (1999).

32. Ricci, J. E. et al. Disruption of mitochondrial function during apoptosis is mediated by caspase cleavage of the p75 subunit of complex I of the electron transport chain. Cell 117, 773-786 (2004).

33. Ricci, J. E., Gottlieb, R. A. \& Green, D. R. Caspase-mediated loss of mitochondrial function and generation of reactive oxygen species during apoptosis. J. Cell Biol. 160, 65-75 (2003).

34. Li, P. et al. Cytochrome $\mathrm{c}$ and dATP-dependent formation of Apaf-1/caspase-9 complex initiates an apoptotic protease cascade. Cell 91, 479-489 (1997). 